\title{
MOSiC (3C, 4H and 6H) Transistors 130nm by BSIM3v3 Model in Low Voltage and Low Power
}

\author{
Mourad Hebali $^{1, *}$, Djilali Berbara ${ }^{1}$, Mohammed Benzohra ${ }^{2}$, Djilali Chalabi ${ }^{1}$, Abdelkader Saïdane ${ }^{1}$ and \\ Abdelkader Baghdad Bey ${ }^{3}$
}

${ }^{1}$ Department of Electrical Engineering, ENP Oran, Laboratory CaSiCCe, 31000 Oran, Algeria

${ }^{2}$ Department of Networking and Telecommunications, University of Rouen, Laboratory LECAP, 76000, France

${ }^{3}$ Department of Science and Technology, University of Mascara, 29000, Algeria

Received 1 August 2017; Accepted 11 November 2017

\begin{abstract}
Silicon carbide is a very interesting semiconductor for applications in high temperature, high frequency and high power. In this article, we have studied and compared MOS transistors with $130 \mathrm{~nm}$ silicon carbide (3C-SiC, $4 \mathrm{H}-\mathrm{SiC}$ and $6 \mathrm{H}-\mathrm{SiC})$ technologies using BSIM3v3 model. To perform this work we have used PSpice to study the characteristics I(V) and the transconductance $\mathrm{gm}$ as a function of temperature in the range $-200^{\circ} \mathrm{C}$ to $750^{\circ} \mathrm{C}$ with a supply voltage $\mathrm{VDS}=1.2 \mathrm{~V}$. We have also calculated the transition frequencies fT of the three types of transistors. Our results show that the $(3 \mathrm{C}, 4 \mathrm{H}$ and $6 \mathrm{H})$ - $\mathrm{SiC}$ transistors operate under a low voltage, low power, high temperature and high frequency in submicron dimension.
\end{abstract}

Keywords: 3C-SiC, 4H-SiC, 6H-SiC, BSIM3v3, MOSFET

\section{Introduction}

Silicon carbide is a wide bandgap semiconductor. It has a high breakdown field, a high saturation velocity of electrons and a high thermal conductivity [01]. This semiconductor is generally used to manufacture electronic components which support high voltages and powers [02]. In our work, we will use BSIM3v3 as model for our silicon carbide transistors (3C-SiC, $4 \mathrm{H}-\mathrm{SiC}$ and $6 \mathrm{H}-\mathrm{SiC}$ ). Based on the equations of this model [03-04], we will calculate our components, then simulate their characteristics $I_{D}=f\left(V_{D S}\right)$, the transfer $I_{D}=f$ $\left(\mathrm{V}_{\mathrm{GS}}\right)$ and transconductance $\mathrm{g}_{\mathrm{m}}=\mathrm{f}(\mathrm{T})$. Our work will be carried for $130 \mathrm{~nm}$ channel length, $1.2 \mathrm{~V}$ supply voltage and temperatures between $-200^{\circ} \mathrm{C}$ and $750^{\circ} \mathrm{C}$. We will use the small signal equivalent circuit for a MOSFET, to determine the transition frequencies $f_{T}$ of different devices.

\section{Description of the transistor}

To realize a comparison, we use a same structure for different MOS transistors in technologies 3C-SiC, 4H-SiC and $6 \mathrm{H}-\mathrm{SiC}$ (Fig- 1).

In order to perform a comparison between different transistors, we will calculate their PSpice parameters taking the same structure for each one (dimensions and doping), as it is shown in table- 1 .

\section{Simulation results and discussion}

3.1 Output characteristics $I_{D}=f\left(V_{D S}\right)$

To characterize the three NMOSiC transistors in direct

*E-mail address: hebalimourad@yahoo.fr

ISSN: 1791-2377 @ 2017 Eastern Macedonia and Thrace Institute of Technology. All rights reserved. doi:10.25103/jestr.105.24 polarization mode, we have applied a voltage $\mathrm{V}_{\mathrm{GS}}$ of $1.2 \mathrm{~V}$ and varied $\mathrm{V}_{\mathrm{DS}}$ from 0 to $1.2 \mathrm{~V}$ with $0.2 \mathrm{~V}$ step . The voltaje values of $V_{D S}$ were chosen so as to distinguish the two regions of operation (linear and saturation). After simulation, we obtained the characteristics of Fig- 2.

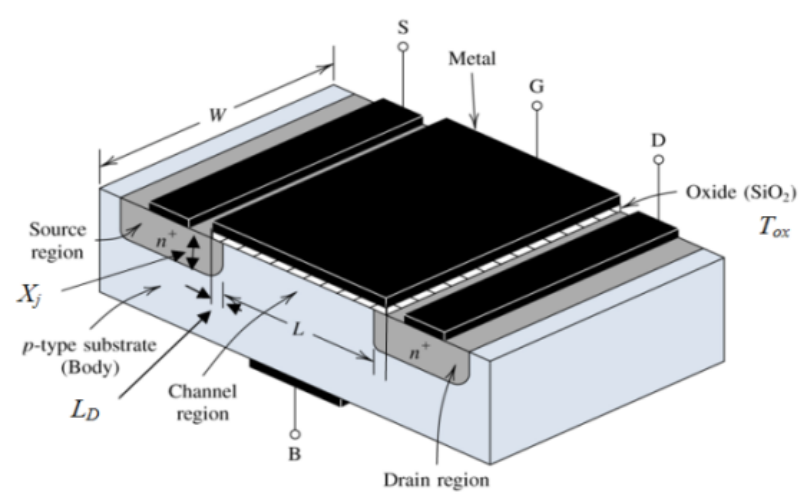

Fig. 1. Structure used of MOSiC transistors.

Fig- 2 shows that the two functional parts of our three transistors are distinct. Ohmic parte (linear) is located for $\mathrm{V}_{\mathrm{DS}}$ below $0.6 \mathrm{~V}$ for $4 \mathrm{H}-\mathrm{SiC}$ and $6 \mathrm{H}-\mathrm{SiC}$ based transistors, however for $3 \mathrm{C}-\mathrm{SiC}$ transistor, it is up to $1 \mathrm{~V}$. The $\mathrm{SiC}$ based transistors designed for high voltages and high powers may function well at low voltages and low powers. The $3 \mathrm{C}-\mathrm{SiC}$ transistor is characterized by a drain current 5 times greater than that of $6 \mathrm{H}-\mathrm{SiC}$ transistor and 15 times greater than that of $4 \mathrm{H}-\mathrm{SiC}$ transistor.

For BSIM3v3 model the drain current can be expressed as [03]: 
$I_{D S}=\frac{\mu_{e f f} C_{o x} W E_{s a t}}{E_{s a t} L+V_{D S}}\left(V_{g S}-V_{t h}-\frac{A_{b u l k} V_{D S}}{2}\right) V_{D S}=a\left(V_{g S}-\right.$

$\left.V_{t h}-\frac{A_{\text {bulk }} V_{D S}}{2}\right) V_{D S}$

Table 1. Control parameters of the model.

\begin{tabular}{c|c|c}
\hline Parameters & Description & values \\
\hline Level & Level model selector & 7 \\
\hline Version & Model version number & 1 \\
\hline MobMod & Mobility model selector & 3 \\
\hline CapMod & Flag for the short channel capacitance model & $2.5 \mathrm{E}-9$ \\
\hline $\mathrm{T}_{\mathrm{ox}}$ & Junction Depth $(\mathrm{m})$ & $1 \mathrm{E}-7$ \\
\hline $\mathrm{X}_{\mathrm{j}}$ & Doping depth $(\mathrm{m})$ & $1.05 \mathrm{E}-7$ \\
\hline $\mathrm{X}_{\mathrm{t}}$ & Gate, Drain and source doping concentration $\left(\mathrm{cm}^{-3}\right)$ & $1 \mathrm{E} 20$ \\
\hline $\mathrm{Ng}=\mathrm{Nd}=\mathrm{Ns}$ & Substrate doping concentration $\left(\mathrm{cm}^{-3}\right)$ & $6 \mathrm{E} 17$ \\
\hline $\mathrm{Nsub}$ & Channel doping concentration $\left(\mathrm{cm}^{-3}\right)$ & $2.36 \mathrm{E} 17$ \\
\hline $\mathrm{N}_{\mathrm{ch}}$ & Maximum applied body bias in Vth calculation & -3 \\
\hline $\mathrm{VBM}$ & Channel length $(\mathrm{nm})$ & 130 \\
\hline $\mathrm{L}$ & Channel width $(\mathrm{nm})$ & 160 \\
\hline $\mathrm{W}$ & &
\end{tabular}

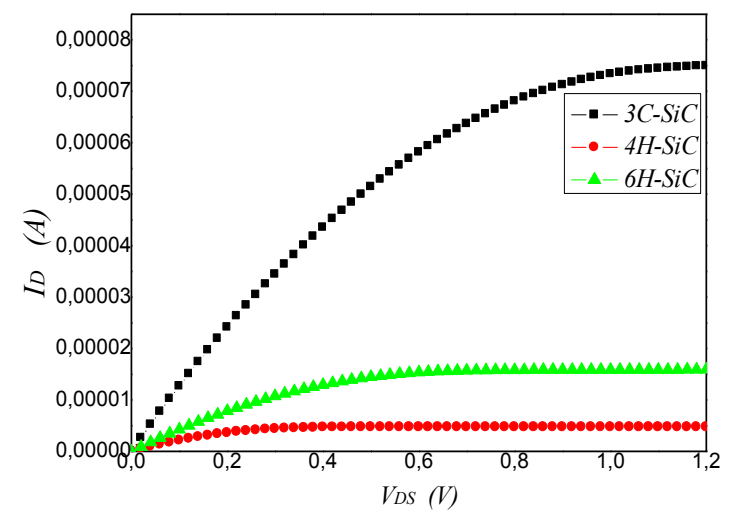

Fig. 2. Output Characteristics $I_{D}=f\left(V_{D S}\right)$ of NMOSiC transistors.

The geometric structure and oxide type used is the same for the three NMOSiC transistors. The ratio $\boldsymbol{a}$ is approximately the same for different transistors. Drain current is inversely proportional to the threshold voltage.

Where the threshold voltage $V_{t h}$ increases, the expression $\left(V_{g s}-V_{t h}-\frac{A_{b u l k} V_{D S}}{2}\right)$ decreases and as in SiC technology, $V_{t h(3 C-S i C)}<V_{t h(6 H-S i C)}<V_{t h(4 H-S i C)}$, the drain current of $3 \mathrm{C}-\mathrm{SiC}$ transistor is greater than the others, as it is illustrated in Figure 2. From our results, we conclude that the $4 \mathrm{H}-\mathrm{SiC}$ transistor technology is characterized by a low power compared to others $(\mathrm{MO}(3 \mathrm{C}-\mathrm{SiC})$ and $\mathrm{MO}(6 \mathrm{H}-\mathrm{SiC}))$ transistors. The band-gap narrowing principle [05-06-07-08]. Submicron technology and charge carriers concentration are directly responsible of the operation of our transistors at low voltage and low power. Based on our results, we conclude that the $4 \mathrm{H}-\mathrm{SiC}$ transistor is characterized by a low power compared to the other $\mathrm{MO}(3 \mathrm{C}-\mathrm{SiC})$ and $\mathrm{MO}(6 \mathrm{H}-\mathrm{SiC})$ transistors.

\subsection{Transfer characteristics $I_{D}=f\left(V_{G S}\right)$}

For the simulation of transfer characteristics $I_{D}=f\left(V_{G S}\right)$ for NMOSiC transistors we have applied a voltage $\mathrm{V}_{\mathrm{DS}}=1.2 \mathrm{~V}$, and we varied the $\mathrm{V}_{\mathrm{GS}}$ voltage from $0 \mathrm{~V}$ to $1.2 \mathrm{~V}$. The results of our simulation are presented in Fig- 3.

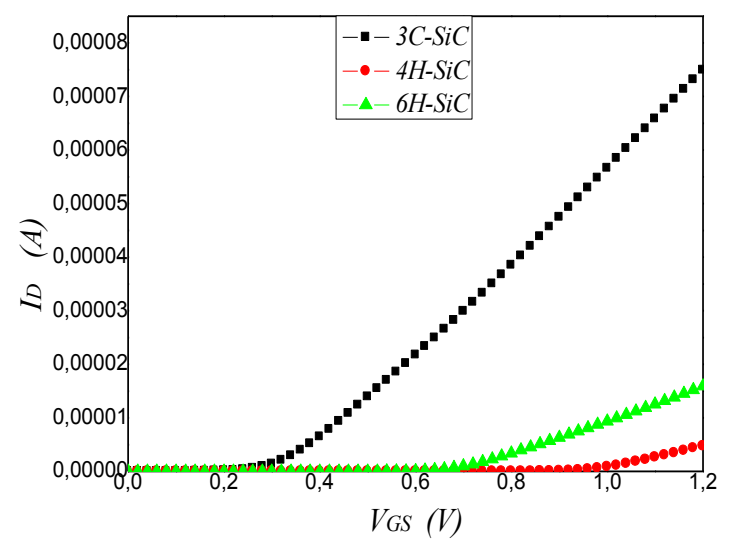

Fig. 3. Transfer characteristic $I_{D}=f\left(V_{G S}\right)$ of the NMOSiC transistors.

4H-SiC NMOS transistor is characterized by a high value of threshold voltage compared to $6 \mathrm{H}-\mathrm{SiC}$ transistor, and the latter has a threshold voltage higher than the 3C-SiC transistor.

The geometric structure, oxide type used and doping technology are the same for different MOSiC transistors.

The parameters which influence the evolution of threshold voltage of the different MOS transistors by considering BSIM3v3 model (expression 1) [04] are: the carrier concentration $\mathbf{n}$ and the gap $\mathbf{E g}$ of each semiconductor.

- Once the gap of semiconductor increases, threshold voltage also increases.

- Once the carrier concentration increases, threshold voltage decreases.

The electrical characteristics $\left(I_{D}=f\left(V_{D S}\right)\right.$ and $I_{D}=f$ $\left(\mathrm{V}_{\mathrm{GS}}\right)$ ) of our transistors in $4 \mathrm{H}-\mathrm{SiC}$ and $6 \mathrm{H}-\mathrm{SiC}$ technology, are similar to those obtained by Md Hasanuzzaman [09] and Vickram R. [10], but there is a contradiction between our result and the result of Jędrzej Stęszewski [05] due to several reasons such as the model of transistors, simulator type and the electronic properties of SiC semiconductors. 


\subsection{Influence of temperature on the transconductance $g_{m}$} (T)

To investigate the evolution of the transconductance $\boldsymbol{g}_{\boldsymbol{m}}$ of a MOS transistor as a function of temperature, we would exploit the transfer characteristic $I_{D}=f\left(V_{D S}\right)$. The transconductance is determined by the following relation [04]:

$g_{m}=\frac{\Delta I_{D S}}{\Delta V_{G S}}$

Based on this relation the transconductance were identified as shown in the following figure:

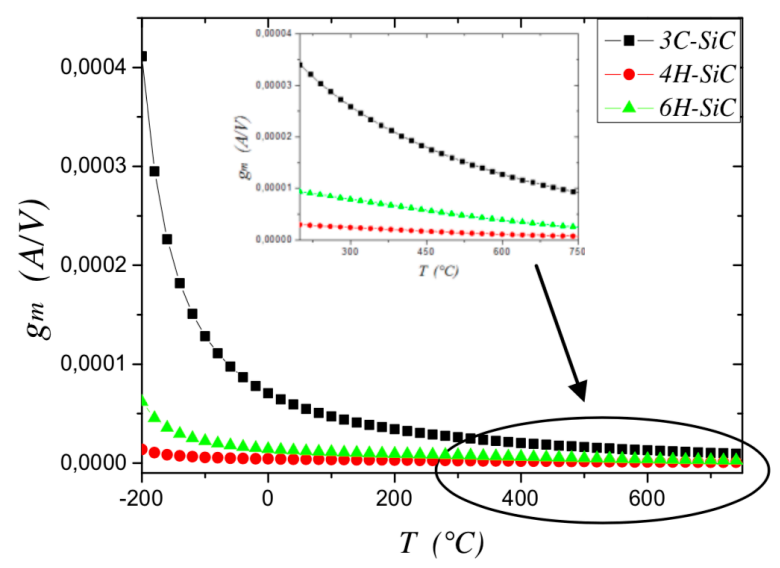

Fig. 4. Transconductance as function of temperature of the NMOS transistors.

The simulated transistors operate in saturation region $\left(\mathrm{V}_{\mathrm{DS}}>\mathrm{V}_{\mathrm{dsat}}\right)$. Starting from the BSIM3v3 model drain relation in this region [04] and following a simplification, expression of transconductance can be written [11]:

$g_{m}(T)=W C_{o x} v_{s a t}(T)=\frac{1}{2} W C_{o x} E_{e f f} \mu_{e f f}(T)$

The transconductance is an important electrical parameter that characterizes MOS transistor in order to study its performances [12]. The saturation velocity and carrier mobility decrease when temperature increase [03]. Then the transconductance $\boldsymbol{g}_{\boldsymbol{m}}$ is directly proportional to the derivative of mobility with respect to gate voltage $\mathrm{V}_{\mathrm{GS}}$ [13], and is proportional to saturation velocity as shown in Fig- 3. The maximum operating temperature of silicon carbide is very high [14]. In our work, we simulated our components in temperature range of $-200^{\circ} \mathrm{C}$ to $750^{\circ} \mathrm{C}$. For that, we found the variation in transconductance $\boldsymbol{g}_{\boldsymbol{m}}$ as function of temperature as indicated in Fig- 4. The studied transistors have yielded satisfactory results in this range.

\subsection{Frequency-response of MOSiC transistors}

For the dynamic study, we have attacked our devices with low amplitude analog complex signal. We have adopted the high frequency equivalent circuit of Fig- 5.

The different transistors are in saturation mode, the transition frequency of a MOS transistor is related to the electrical elements values of the equivalent circuit diagram (Fig- 5).

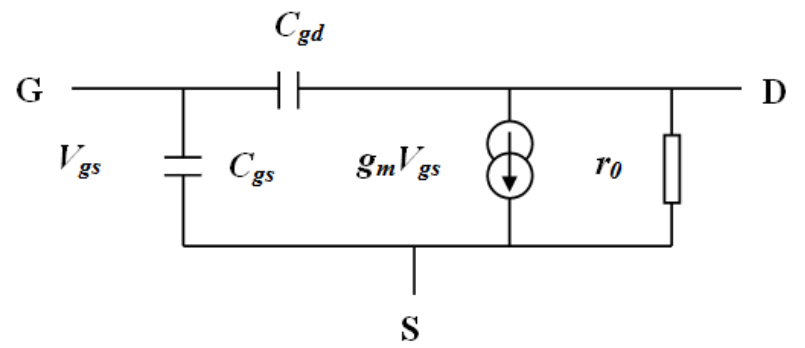

Fig. 5. Equivalent circuit small signal MOS transistor [15].

Transition frequency expression of MOS transistors is [16-17]:

$f_{T}=\frac{g_{m}}{2 \pi\left(C_{g s}+C_{g d}\right)}$

With $g_{m}$ Transconductance in saturation mode.

$\mathrm{C}_{\mathrm{gs}}$ and $\mathrm{C}_{\mathrm{gd}}$ : Gate-Source and Gate- Drain capacity . They are given by equations (5) and (6).

$C_{g s}=\frac{2}{3} W L C_{o x}+W L_{o v} C_{o x}$

$C_{g d}=W L_{o v} C_{o x}$

With $L_{o v}=\frac{C_{g d o}}{C_{o x}}$ where $C_{\text {gdo }}$ is PSpice parameter of BSIM3v3 model.

The structure dimensions and oxide type used are the same for the three types of studied transistors. Then, the expression $2 \pi\left(C_{g s}+C_{g d}\right)$ depends only on transistor dimensions and oxide capacitor $\mathrm{C}_{\mathrm{ox}}$. Its value is the same for the three types of MOSiC transistor. Thus, the transition frequency is directly proportional to transconductance of transistors.

In Table- 3, we carry the frequencies determined together with a summary of different determined results.

From our results, we conclude that the $3 \mathrm{C}-\mathrm{SiC}$ technology transistor is characterized by high operating frequency compared with other transistors $(\mathrm{MO}(4 \mathrm{H}-\mathrm{SiC})$ and $\mathrm{MO}(6 \mathrm{H}-$ $\mathrm{SiC})$ ).

Table- 2 shows the comparison between our MOS transistors of the different $\mathrm{SiC}$ technologies.

Table 2. Results of the different parameters determined of MOSiC transistors.

\begin{tabular}{c|c|c|c}
\hline Parameters & $\begin{array}{c}\text { MOS(3C- } \\
\text { SiC) }\end{array}$ & $\begin{array}{c}\text { MOS(4H- } \\
\text { SiC) }\end{array}$ & $\begin{array}{c}\text { MOS(6H- } \\
\text { SiC) }\end{array}$ \\
\hline $\mathrm{I}_{\text {Dsat }}(\mu \mathrm{A})($ to & 74.946 & 4.7449 & 15.903 \\
$\left.\mathrm{~V}_{\mathrm{GS}}=1.2 \mathrm{~V}\right)$ & & & \\
$\mathrm{V}_{\text {th }}(\mathrm{V})$ & 0.38 & 1 & 0.71 \\
$\begin{array}{c}\text { Operating } \\
\text { temperature }\left({ }^{\circ} \mathrm{C}\right)\end{array}$ & $\geq 700$ & $\geq 550$ & $\geq 600$ \\
$f_{T}(\mathrm{GHz})$ & 42.24 & 9.8049 & 15.099 \\
\hline
\end{tabular}

In our work, we have shown that the MOS transistors in silicon carbide submicron technology work well in low voltage, low power, high frequency and a wide temperature range. 


\section{Conclusion}

Our MOSiC transistors $(3 \mathrm{C}, 4 \mathrm{H}$ and $6 \mathrm{H})$ are calculated for $130 \mathrm{~nm}$ technology, then simulated by OrCAD 16.5 software (PSpice) BSIM3v3. We have shown that the energy gap and carrier concentration are responsible for the evolution of different electronic characteristics of our transistors. Our simulation shows that our MOSiC transistors operate correctly in a temperature range of $-200^{\circ} \mathrm{C}$ to $750{ }^{\circ} \mathrm{C}$ for $1.2 \mathrm{~V}$ supply voltage. The transition frequencies are relatively high. They can reach about forty $\mathrm{GHz}$. SiC transistors are designed to operate in high voltage and high power. We have demonstrated that they can be submicron and they operate at low voltage, low power and high temperatures

Access article distributed under the terms of the Creative Commons Attribution License

\section{(c)}

\section{Reference}

1. Laurence Latu-Romain Maelig Ollivier "Silicon Carbide Onedimensional Nanostructures" ISTE Ltd (2015)-WILEY-Library of Congress Control Number: 2014955862.

2. Hans-Erik Nilsson, Kent Bertilsson, Ervin Dubaric, and Mats Hjelm " Numerical Simulation of Field Effect Transistors in $4 \mathrm{H}$ and $6 \mathrm{H}-\mathrm{SiC} "$ IEEE. 3rd International Conference on Novel Applications of Wide Bandgap Layers.2001.pp 199 - 200.

3. Yuhua Cheng and Chenming $\mathrm{Hu}$ " MOSFET MODELING \& BSIM3 USER'S GUIDE”' University of California, Berkeley.2002.

4. Weidong Liu, XiaodongJin “ BSIM3V3.3 MOSFET Users" Manual" University of California, Berkeley.2005.

5. Jędrzej Stęszewski, Andrzej Jakubowski, and Michael L "Copmarison of $4 \mathrm{H}-\mathrm{SiC}$ and $6 \mathrm{H}-\mathrm{SiC}$ MOSFET I-V characteristics simulated with Silvaco Atlas and Crosslight Apsys" Journal of Telecommunications \& Information Technology .2007 (3). 2007. pp 93-95.

6. A. Galeckas, P. Grivickas, V. Grivickas, V. Bikbajevas , and J. Linnros "Temperature Dependence of the Absorption Coefficient in $4 \mathrm{H}-$ and 6H-Silicon Carbide at $355 \mathrm{~nm}$ Laser Pumping Wavelength" phys. stat. sol. (a). 191(2). 2002. pp 613-620.

7. W.J. Choyke and L. Patrick, Phys. Rev. 105, 1721 (1957).

8. C. Persson, U. Lindefelt, and B. Sernelius, Phys. Rev. B 60, 16479 (1999).

9. Md Hasanuzzaman, Syed K. Islam, Leon M. Tolbert, Mohammad T. Alam "Temperature dependency of MOSFET device characteristics in $4 \mathrm{H}$ - and $6 \mathrm{H}$-silicon carbide $(\mathrm{SiC})$ " Solid-State Electronics . (48). 2004. pp 1877-1881.

10. Vickram R. Vathulya, and Marvin H. White "Characterization of Inversion and Accumulation Layer Electron Transport in $4 \mathrm{H}$ and 6H-SiC MOSFETs on Implanted P-Type Regions" IEEE Transactions on Electron Devices. 47 (11). 2000. pp 2018 - 2023.

11. PAUL R. GRAY, PAUL J. HURST, STEPHEN H. LEWIS, and ROBERT G. MEYER “ Analysis and of Analog Integrated Circuits "Fifth Edition- WILEY-2009.

12. D.Chalabi, A.Saidane, M.Idrissi-Benzohra, and M.Benzohra "Thermal behavior Spice study of $6 \mathrm{H}-\mathrm{SiC}$ NMOS transistors" Microelectronics journal .40 . 2009. pp 891-896.

13. CHALABI Djilali, PhD thesis, USTO, (2005).

14. Laurence Latu-Romain Maelig Ollivier "Silicon Carbide Onedimensional Nanostructures" Edition 2015- ISTE Ltd 27-37 St eorge's Road- Library of Congress Control Number: 2014955862WILEY.

15. Renaud DAVIOT, PhD thesis, L'Institut National des Sciences Appliquées de Lyon, (2006).

16. H.Beneking "HIGH SPEED SEMICONDUCTOR DEVICES Circuit aspects and fundamental behavior" First edition (1994), ISBN 0412562200 6, Library of Congress Catalog Card Number: 94-70972. CHAPMAN \& HALL.

17. M.Willander and H.L.Hartnagel "High Temperature Electronics" First edition (1997)- ISBN 041262510 5- Library of Congress Catalog Card Number: 96-86291. CHAPMAN \& HALL. 